\title{
Review
}

\section{The role of PML in the control of apoptotic cell fate: a new key player at ER-mitochondria sites}

\author{
P Pinton ${ }^{1,3}$, C Giorgi ${ }^{1,3}$ and PP Pandolfi, ${ }^{\star, 2}$
}

The development of malignant tumors results from deregulated proliferation or an inability of cells to undergo apoptotic cell death. Experimental works of the past decade have highlighted the importance of calcium $\left(\mathrm{Ca}^{2+}\right)$ in the regulation of apoptosis. Several studies indicate that the $\mathrm{Ca}^{2+}$ content of the endoplasmic reticulum (ER) determines the cell's sensitivity to apoptotic stress and perturbation of $\mathrm{ER} \mathrm{Ca}^{2+}$ homeostasis appears to be a key component in the development of several pathological situations. Sensitivity to apoptosis depends on the ability of cells to transfer $\mathrm{Ca}^{2+}$ from the ER to the mitochondria. The physical platform for the interplay between the ER and mitochondria is a domain of the ER called the mitochondria-associated membranes (MAMs). The disruption of these contact sites has profound consequences for cellular function, such as imbalances of intracellular $\mathrm{Ca}^{2+}$ signaling, cellular stress, and disrupted apoptosis progression. The promyelocytic leukemia (PML) protein has been previously recognized as a critical and essential regulator of multiple apoptotic response. Nevertheless, how PML would exert such broad and fundamental role in apoptosis remained for long time a mystery. In this review, we will discuss how recent results demonstrate that the elusive mechanism whereby the PML tumor suppressor exerts its essential role in apoptosis triggered by $\mathrm{Ca}^{2+}$-dependent stimuli can be attributed to its unexpected and fundamental role at MAMs in the control of the functional cross-talk between ER and mitochondria.

Cell Death and Differentiation (2011) 18, 1450-1456; doi:10.1038/cdd.2011.31; published online 8 April 2011

\section{The Promyelocytic Leukemia Protein}

The promyelocytic leukemia (PML) protein is a tumor suppressor gene originally identified at the break point of the $t(15 ; 17)$ chromosomal translocation of acute promyelocytic leukemia (APL), a distinct subtype of acute myeloid leukemia. As a consequence of this translocation, PML fuses to the retinoic acid (RA) receptor alpha $(R A R \alpha)$ gene. Two fusion genes are generated encoding PML-RAR $\alpha$ and RAR $\alpha-P M L$ fusion proteins, which coexist in the leukemic cells, blocking heamatopoietic differentiation (for a review, see Pandolfi; ${ }^{1}$ Salomoni and Pandolfi. ${ }^{2} \mathrm{PML}$ has, therefore, become the object of intense research on the basis of this premise. Since then, PML has been shown to regulate diverse cellular functions, such as transcriptional regulation, DNA-damage response, sumoylation process, cellular senescence, neoangiogenesis, and, of relevance to this review, apoptosis. ${ }^{3,4}$

PML belongs to a large family of proteins harboring a tripartite structure that contains a zinc-finger called the RING motif $(R)$ located N-terminally followed by two additional zincfingers motifs (B-boxes; $B$ ) and an $\alpha$-helical coiled-coil domain
(CC), collectively referred to as the RBCC domain. The RBCC domain mediates protein-protein interactions and is responsible for PML multimerization and the formation of macromolecular complexes. The C-terminal region of $\mathrm{PML}$ is less structured and varies between PML isoforms. Alternative splicing of $\mathrm{C}$-terminal exons is responsible for the existence of at least seven PML isoforms characterized by different $\mathrm{C}$-terminal regions and functional specificity. ${ }^{4,5}$

$\mathrm{PML}$ is typically concentrated in subnuclear macromolecular structures termed PML-nuclear bodies (PML-NBs), of which $P M L$ is the essential component. PML-NBs have a diameter of $0.2-1 \mu \mathrm{m}$ and the shape of a doughnut. PML-NBs are multiprotein dynamic structures that undergo significant changes in number, size, and position, particularly in response to cellular stress. ${ }^{4,6}$ They critically depend on PML to be correctly assembled. $^{7}$

PML functionally interacts with a large number of proteins within PML-NBs. ${ }^{4,6}$ Some are in direct physical contact with PML, while others are not. ${ }^{4,6}$ PML SUMOylation and noncovalent binding of PML to SUMOylated PML through the

\footnotetext{
${ }^{1}$ Department of Experimental and Diagnostic Medicine, Section of General Pathology, Interdisciplinary Center for the Study of Inflammation (ICSI) and LTTA center, University of Ferrara, Ferrara, Italy and ${ }^{2}$ Departments of Medicine and Pathology, Cancer Genetics Program, Beth Israel Deaconess Cancer Center, Beth Israel Deaconess Medical Center, Harvard Medical School, Boston, MA, USA

${ }^{*}$ Corresponding author: PP Pandolfi, Departments of Medicine and Pathology, Beth Israel Deaconess Medical Center, Harvard Medical School, 330 Brookline Avenue CLS 0424, Boston, MA 02215, USA. Tel: 617667 3289; Fax: 617667 3330; E-mail: ppandolf@ bidmc.harvard.edu

${ }^{3}$ These authors contributed equally to this work.

Keywords: PML; mitochondria; endoplasmic reticulum (ER); apoptosis; calcium $\left(\mathrm{Ca}^{2+}\right)$; mitochondria-associated membranes (MAMs)

Abbreviations: AML, acute myeloid leukemia; APL, acute promyelocytic leukemia; ANT, adenine nucleotide translocator; $\mathrm{Ca}^{2+}$, calcium; cypD, cyclophilin D; ER, endoplasmic reticulum; IP3, inositol 1,4,5-trisphosphate; IP3Rs, IP3-sensitive $\mathrm{Ca}^{2+}$ release channels; MAMs, mitochondria-associated membranes; MEFs, mouse embryonic fibroblasts; PML, promyelocytic leukemia; PML-NBs, PML-nuclear bodies; nuPML, PML chimera targeted to the nucleus; erPML, PML chimera targeted to the outer surface of the ER; RA, retinoic acid; RAR $\alpha$, retinoic acid receptor alpha; VDAC, voltage-dependent anion channel

Received 19.1.11; revised 18.2.11; accepted 18.2.11; Edited by G Melino; published online 08.4.11
} 
SUMO-binding motif constitutes the nucleation event for subsequent recruitment of SUMOylated proteins and/or proteins containing SUMO-binding motifs to the PML NBs. ${ }^{7}$

In the APL blasts, PML-RAR $\alpha$ associates physically with PML and causes its delocalization into microspeckled nuclear structures with consequent disruption of the PML-NBs. ${ }^{8}$ Loss of $\mathrm{PML}$ in a mouse model of $\mathrm{APL}$ causes a dramatic acceleration of leukemia and increased incidence of the disease, indicating the importance of the functional disruption of PML and PML-NBs for disease progression. ${ }^{1,9}$ Moreover, PML has been more recently shown to modulate the subcellular localization of the tumor suppressor PTEN. ${ }^{10}$ As a consequence, both in APL blasts and in PML-loss conditions, PTEN is excluded from the nucleus, ${ }^{11}$ in turn suggesting that PTEN delocalization and loss of its nuclear function may have an important role in the pathogenesis of this and possibly other forms of leukaemia. Treatment with drugs commonly used for APL, ${ }^{11}$ such as all-trans RA or arsenic trioxide, restores normal nuclear PTEN localization. ${ }^{10}$

$\mathrm{Pml}$ null mice and cells are protected from multiple and diverse apoptotic stimuli (Figure 1). ${ }^{12}$ A possible explanation for why $\mathrm{Pml}$ null cells are resistant to many apoptotic stimuli can be ascribed to the fact that PML can act as a pleiotropic factor in the functional regulation of several pro- and antiapoptotic factors. ${ }^{13}$

Indeed, PML is functioning as part of a complex tumorsuppressive network. For instance, it is well established that PML is an important factor in the regulation of both p53dependent and -independent apoptotic pathways. ${ }^{13,14} \mathrm{PML}$ activates $p 53$ by several means: by recruiting p53 to PML-NBs by promoting its acetylation and phosphorylation, ${ }^{15-18}$ and by binding and inhibiting Mdm2, the main negative regulator of p53, ${ }^{19-21}$ as well as by promoting p53 de-ubiquitination by the ubiquitin protease HAUSP. 22,23

Moreover, PML can act as a suppressor of other major oncogenic pathways, such as the PI3K/Akt pathway, through its ability to interact with the protein phosphatase PP2A and inhibit the nuclear function of Akt, thus leading to suppression of its prosurvival and promitogenic functions. ${ }^{24}$ In Pten ${ }^{+/}$ animals, reduction of the $\mathrm{Pml}$ gene dosage results in transition

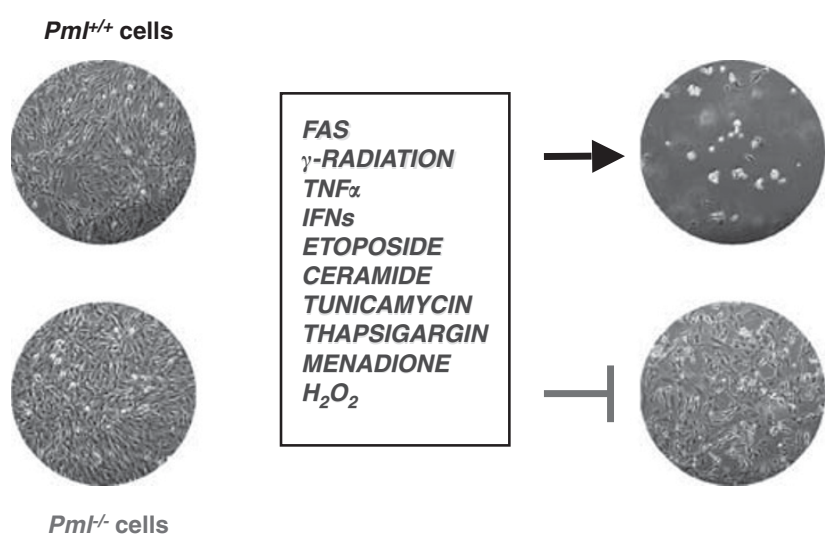

Figure $1 \mathrm{PML}$ is critical in multiple apoptotic pathways. The absence of PML inhibits cell death induced by various apoptotic stimuli. PML is critical for both transcription-dependent (e.g., p53-mediated responses) responses as well as transcription-independent early apoptotic responses to invasive carcinoma, which is accompanied by increased Akt phosphorylation, ${ }^{24}$ suggesting a genetic interaction between the two pathways. Finally, as aforementioned, PML regulates the function of the PTEN, which is the main suppressor of the PI3K pathway. This occurs through inhibition of PTEN de-ubiquitination by HAUSP and its nuclear retention. ${ }^{11,25,26}$ In conclusion, PML-NBs emerge as signaling coordination centers toward the regulation, availability, posttranslational modification, and activation of multiple and diverse proteins implicated in apoptotic pathways.

However, no unified mechanism appeared to explain the global resistance of Pml null cells to apoptosis. Moreover, all these observations failed to clarify whether or not PML might also be involved directly in the execution of the apoptotic response and if the extra-nuclear fraction of $P M L$ could have a role in this respect. Indeed, in addition to its nuclear localization, some PML isoforms are found to accumulate into the cytosolic fraction, ${ }^{5}$ as well as adjacent to mitochondria, ${ }^{27}$ and to be critical in the regulation of TGF- $\beta$ signaling and anti-viral responses. ${ }^{28,29}$

More recently, fractionation analysis by ultracentrifugation, immunogold labeling, and immunofluorescence in mouse embryonic fibroblasts (MEFs) revealed that PML associates to the surface of endoplasmic reticulum (ER) and in the proximity of the mitochondrial membrane at the $\mathrm{ER} /$ mitochondria contact sites (MAMs; mitochondria-associated membranes) (Figure 2), suggesting that PML might have additional as yet unidentified functions independent from the PML-NB. ${ }^{30}$

Importantly, this unexpected intracellular localization of PML has been observed also in vivo through fractionation analysis of mouse liver cells (Giorgi, Pinton, and Pandolfi unpublished observations). Further fractionation experiments and immunohistochemical analysis that takes advantage of PML-specific antibodies will address whether the localization of PML at MAM is tissue specific or rather ubiquitous.

\section{The ER-Mitochondria Contact Sites as a Hot Spot Signaling Unit}

Mitochondrial and ER networks are fundamental for the maintenance of cellular homeostasis and for the determination of cell fate under stress conditions. ${ }^{31}$ Structural and functional studies revealed that as much as $20 \%$ of the mitochondrial surface is in direct contact with the ER, underscoring the dynamic and highly regulated communication between the ER and mitochondria. ${ }^{32}$

These specific zones of close contact between ER and mitochondria have been termed MAMs by Jean Vance who characterized for the first time, from a biochemical point of view, the intimate relationship between the two compartments. ${ }^{33}$

Experiments in living cells with ER and mitochondria differentially labeled by mutants of GFP have subsequently demonstrated the existence of a physical interaction between the two organelles and highlighted the functional importance of these contact sites. ${ }^{32}$

The physiological function of the close apposition between ER and mitochondria is related to bioenergetics and cell survival. 


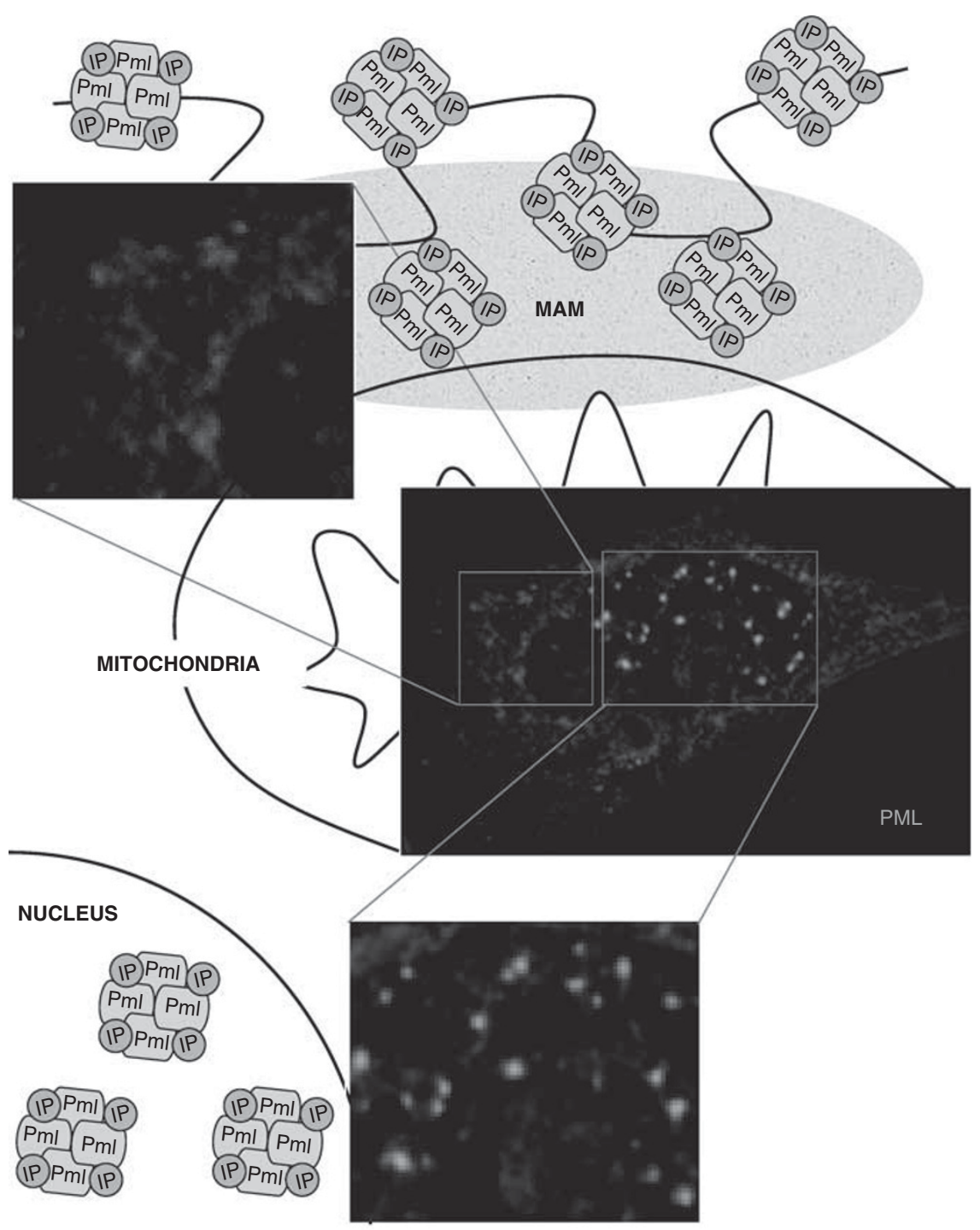

Figure 2 Intracellular localization of PML. The PML protein accumulates in the nucleus where it forms PML-nuclear bodies (PML-NBs), as well as at endoplasmic reticulum $(\mathrm{ER})$ in the contact sites with mitochondria (MAMs). In both sites, PML interacts with several proteins (indicated in figure as IP: interacting proteins) generating multi-protein complexes of large molecular size

MAMs contain multiple phospholipid- and glycosphingolipid-synthesizing enzymes, including long-chain fatty acid-CoA ligase type 4 (FACL4) and phosphatidylserine synthase-1 (PSS-1), and support direct transfer of lipids between the ER and mitochondria. ${ }^{34,35}$

In addition to the function in phospholipid homeostasis, MAMs have been implicated in the metabolism of cholestero ${ }^{36,37}$ and its metabolites and in the trafficking of sphingolipids. ${ }^{38}$

MAMs have also an important role in ER-mitochondrial calcium $\left(\mathrm{Ca}^{2+}\right)$ transfer. In support of this notion, western blot analysis of MAMs fraction after subcellular fractionation showed a selective enrichment of signaling elements, ${ }^{39}$ such as the inositol 1,4,5-trisphosphate (IP3)-sensitive $\mathrm{Ca}^{2+}$ release channels (IP3Rs), ${ }^{40}$ the most important molecular component of $\mathrm{Ca}^{2+}$ handling machinery, identifying these zones as 'hotspots' of $\mathrm{Ca}^{2+}$ transfer from the ER to the mitochondria (Figures 3 and 4).

Interestingly, on the mitochondria side, this specialized domain is enriched in components of the permeability transition pore. ${ }^{41,42}$ This large-conductance channel (which has attracted a large interest given its potential role in pathophysiological conditions) includes the adenine nucleotide translocator (ANT), the voltage-dependent anion channel (VDAC), cyclophilin $\mathrm{D}$, and other proteins (including proapoptotic members of the Bcl-2 family such as BAX/BAK). Both VDAC and ANT were shown by us and other groups to be enriched in the MAMs fraction (Figure 4a). ${ }^{39}$

The continuous flow of $\mathrm{Ca}^{2+}$ between these two organelles regulates processes ranging from ER chaperone-assisted folding of newly synthesized proteins to the regulation of mitochondria-localized dehydrogenases involved in 

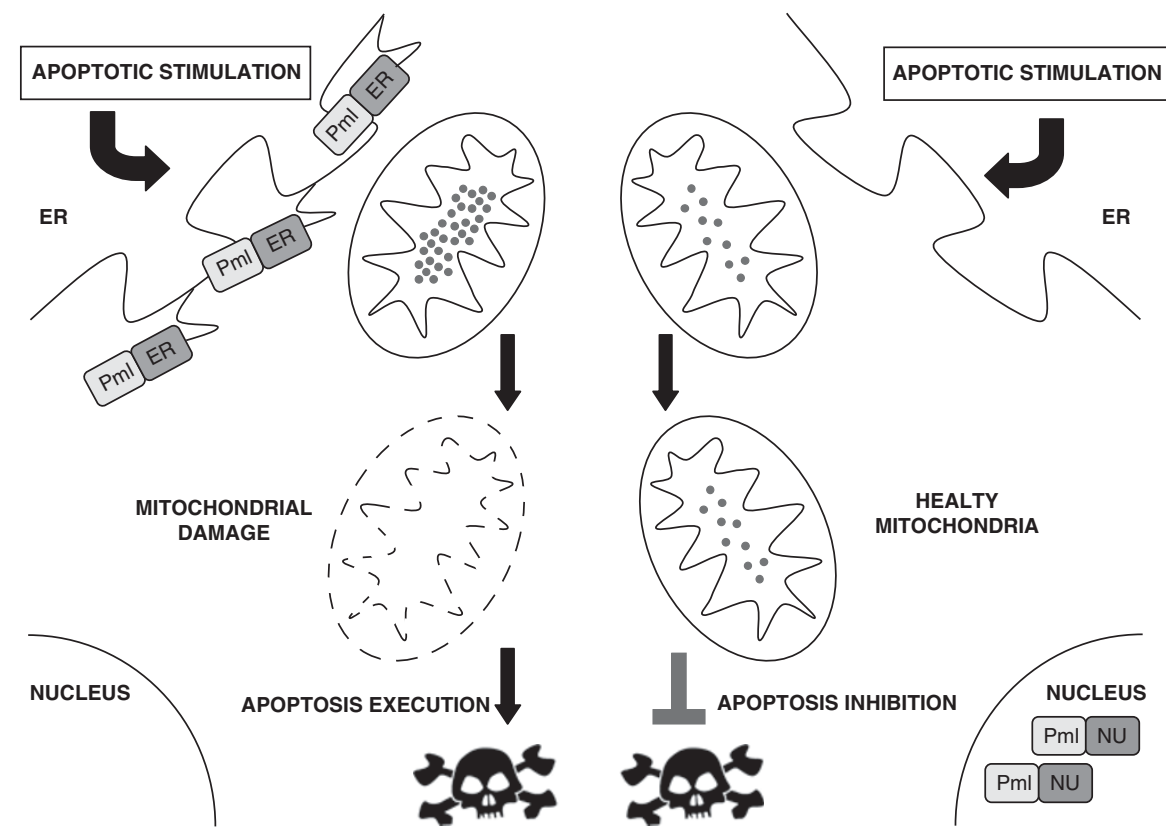

Figure 3 PML localization at ER/MAM is critical for calcium-dependent apoptotic cell death. Re-expression of an erPML chimera does rescue the sensitivity to cell death of $\mathrm{PML}$ null cells. In this case, the $\mathrm{ER} \mathrm{Ca}{ }^{2+}$ release induced by various apoptotic stimuli causes a mitochondrial $\mathrm{Ca}^{2+}$ overload and in turn the damage of the mitochondrial structure with release of apoptotic factors. On the contrary, the re-introduction of a nuPML chimera is able to rescue the PML-NBs formation, but not the sensitivity to apoptosis. In this case, the absence of PML at the ER/MAMs sites still impairs ER-Ca ${ }^{2+}$ release and in turn mitochondrial damage and the apoptotic response

ATP-producing Krebs cycle reactions, and the activation of $\mathrm{Ca}^{2+}$-dependent enzymes that execute cell death programs. ${ }^{43}$ Hence alterations in the $\mathrm{ER} /$ mitochondrial coupling and in $\mathrm{Ca}^{2+}$ homeostatic mechanisms provides a powerful molecular basis for the activation of apoptosis. ${ }^{31}$

\section{ER/Mitochondrial Coupling in $\mathrm{Ca}^{2+}$ Signal and Apoptosis}

The ER is the main $\mathrm{Ca}^{2+}$ store of the mammalian cell, mitochondria are the powerhouse of the cell and they need $\mathrm{Ca}^{2+}$ signal to carry out their function. If we consider that $\mathrm{Ca}^{2+}$ ion is one of the most important mediators of life and death (and that mitochondria are main effectors of these processes), then the dynamic cross-talk between ER and mitochondria in the regulation of $\mathrm{Ca}^{2+}$ signal becomes a key step in physiology and pathology ${ }^{44}$ (Figure 4).

On this basis, it has been argued that the switch from a life to a death signal occurs when normal $\mathrm{Ca}^{2+}$ distribution between the ER and the mitochondria is distorted leading to a breakdown of mitochondrialfunctions. ${ }^{45}$ During normal signaling, there is a continuous flow of $\mathrm{Ca}^{2+}$ between these two organelles where a small bolus of $\mathrm{Ca}^{2+}$ is periodically released to the cytoplasm to be then re-sequestered with a proportion passing through the mitochondria. ${ }^{46}$

In contrast, perturbation of $\mathrm{ER} /$ mitochondrial coupling provide a massive and/or a prolonged mitochondrial $\mathrm{Ca}^{2+}$ overload that in turn activates apoptosis. ${ }^{44,47}$ Indeed, a wide number of apoptotic stimuli, such as ceramide, arachinodic acid, and oxidative stress induced by $\mathrm{H}_{2} \mathrm{O}_{2}$ or menadione, trigger both a progressive release of $\mathrm{Ca}^{2+}$ from the ER and an activation of the capacitative $\mathrm{Ca}^{2+}$ influx. This sustained ER
$\mathrm{Ca}^{2+}$ release, in turn, induced a mitochondrial $\mathrm{Ca}^{2+}$ overload with a consequent release of mitochondria proteins involved in the apoptotic process, such as cytocrome $c$, AIF, and Smac/ Diablo. ${ }^{44,48}$

In this respect, conditions that reduce the $\mathrm{ER} \mathrm{Ca}^{2+}$ storage and thus $\mathrm{Ca}^{2+}$ released from ER to mitochondria decrease the probability of $\mathrm{Ca}^{2+}$-dependent apoptosis; ${ }^{49}$ on the other hand, an increase in the $\mathrm{Ca}^{2+}$ released has the opposite effect.

Interestingly, over-expression of the anti-apoptotic protein $\mathrm{Bcl}-2$ decreases the steady-state $\mathrm{Ca}^{2+}$ content of the $\mathrm{ER}$, resulting in a reduced amount of agonist-releasable $\mathrm{Ca}^{2+}$ and in a diminution of cytosolic and mitochondrial $\mathrm{Ca}^{2+}$ response. ${ }^{48,50}$ Thus, by diminishing $\mathrm{ER} \mathrm{Ca}^{2+}$ levels, $\mathrm{Bcl}-2$ is able to protect from $\mathrm{Ca}^{2+}$-dependent apoptotic stimuli. ${ }^{51}$ Moreover, knocking out the pro-apoptotics Bax and Bak leads to a dramatic reduction of the steady-state $\mathrm{Ca}^{2+}$ concentration in the ER, rendering the knock-out cells more resistant to apoptosis. ${ }^{52}$ On the contrary, after over-expression of Bax, the $\mathrm{ER} \mathrm{Ca}^{2+}$ content increases and the cells are more susceptible to apoptosis treatment. ${ }^{53}$ Therefore, manipulating the level of $\mathrm{ER} \mathrm{Ca}^{2+}$, adjusting the load of $\mathrm{Ca}^{2+}$ imposed upon mitochondria, it is possible to regulate apoptosis.

This concept was corroborated by the case of PML that was discovered to modulate $\mathrm{Ca}^{2+}$ homeostasis and apoptosis in view of its ability to localize and function at the ER and MAMs, as mentioned above ${ }^{30}$ (Figure 3). Indeed, in the absence of $\mathrm{Pml}$, the ER steady-state values are lower and the decreases of $\left[\mathrm{Ca}^{2+}\right]_{\mathrm{ER}}$ after agonist treatment are drastically smaller and lower compared with $\mathrm{Pml}^{+/+} \mathrm{MEFs}$. In agreement with the observed low $\left[\mathrm{Ca}^{2+}\right]_{\mathrm{ER}}$, the $\left[\mathrm{Ca}^{2+}\right]$ increases evoked in the cytosol and mitochondria both by ATP stimulation and by 


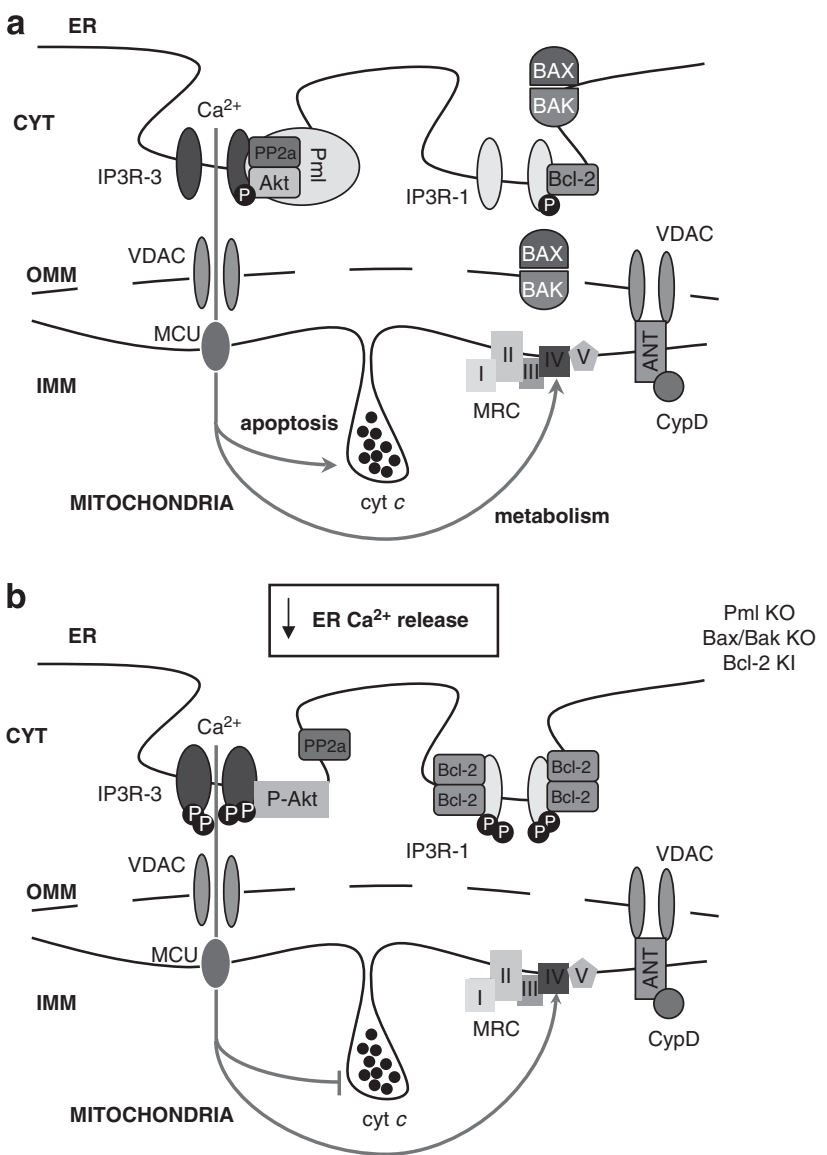

Figure 4 Schematic representation of ER-mitochondria $\mathrm{Ca}^{2+}$ cross-talk perturbations in physiological and oncogenic states. (a) In normal cells, the PML protein is in protein complexes with the type 3 inositol trisphosphate receptor (IP3R-3), the protein kinase Akt and the phosphatase PP2a. This complex is fundamental to regulate the phosphorylation state of IP3R-3, while the Bcl-2-Bax ratio controls the phosphorylation state of the type 1 of IP3R (IP3R-1). In normal conditions, the stimulation of $\mathrm{ER} \mathrm{Ca}^{2+}$ release through IP3 generating stimuli allows a transient mitochondrial $\mathrm{Ca}^{2+}$ uptake and in turn the stimulation of mitochondrial ATP production through the mitochondrial respiratory chain (MRC). In contrast, a $\mathrm{Ca}^{2+}$-dependent pro-apoptotic stimulus induces a much larger $\mathrm{Ca}^{2+}$ release from the ER with a dramatic effect on mitochondria, which induces the release of cytocrome $c$ and the opening of the mitochondrial permeability transition pore. This chain of event, combined with the activation of cytoplasmic effectors, is an important trigger of the apoptotic program. (b) In cancer cells, where PML is often missing or when the Bcl-2-Bax ratio is abnormal, IP3R-3 and IPR1 are, respectively, hyper-phosphorylated as demonstrated on Pml KO, Bax/Bak KO, or Bcl-2 Kl cells. Under these conditions, pro-apoptotic stimuli induce a smaller release of $\mathrm{Ca}^{2+}$ from $\mathrm{ER}$, with minor repercussions on mitochondrial physiology and intracellular $\mathrm{Ca}^{2+}$-modulated processes

oxidative apoptotic stimulation were significantly smaller in $\mathrm{Pm}^{-1-}$ than in $\mathrm{Pml}^{+/+}$MEFs and cells were unable to die. Furthermore, the expression of a PML chimera that exclusively localizes to the outer surface of the ER (erPML) in $\mathrm{Pml}^{-1}$ MEFs restores mitochondrial $\mathrm{Ca}^{2+}$ signals to values comparable to those measured in $\mathrm{Pml}^{+1+} \mathrm{MEFs}$ re-establishing also their sensitivity to the apoptosis. On the contrary, a PML targeted exclusively to the nucleus, restores the formation of NB but is not able to rescue $\mathrm{Ca}^{2+}$ response and the sensitivity to ER-stress-dependent cell death ${ }^{30}$ (Figure 3).
Altogether, these data highlight the link between $\mathrm{Ca}^{2+}$ homeostasis and the regulation of apoptotic cell death and clearly indicate ER/mitochondria contacts as a critical, although not unique checkpoints.

\section{IP3Rs as Target of Cell Death}

The most important molecular component of the $\mathrm{Ca}^{2+}$ handling machinery of the ER is represented by the IP3Rs. IP3Rs are ligand-gated channels that serve to discharge $\mathrm{Ca}^{2+}$ from ER stores in response to agonist stimulation. ${ }^{40,54}$ After IP3-mediated release of $\mathrm{Ca}^{2+}$ from the ER through the IP3 receptor, high- $\mathrm{Ca}^{2+}$ microdomains (estimated to be in the range of $50-100 \mu \mathrm{M}$ ) are generated at the tight ERmitochondrial junctions, activating the low-affinity mitochondrial $\mathrm{Ca}^{2+}$ uniporter and resulting in mitochondrial $\mathrm{Ca}^{2+}$ uptake $^{32}$ (Figure 4).

Being directly responsible for mitochondrial $\mathrm{Ca}^{2+}$ overload, the release of $\mathrm{Ca}^{2+}$ from ER stores by IP3Rs is linked to multiple models of apoptosis. ${ }^{55}$ Indeed, cells deficient of IP3R are resistant to apoptosis ${ }^{56-58}$ (Figure 4).

There are three isoforms of IP3Rs: IP3R-1 to 3. At present, it is not clear whether different IP3 receptor isoforms have an equivalent role in apoptosis, but types 1 and 3 have been described as important in mediating $\mathrm{Ca}^{2+}$-dependent cell death. ${ }^{59}$ Importantly, their function is regulated by posttranscriptional modifications. In particular IP3R phosphorylation appears to be a key common feature for modulation of channel function and, as consequence, apoptotic signaling. ${ }^{60-62}$

In this respect, the Korsmeyer's group found that Bcl-2 and IP3R-1 physically interact at the ER surface and proposed a model by which Bcl-2 family members regulate IP3R-1 phosphorylation to control the rate of $\mathrm{ER} \mathrm{Ca}^{2+}$ leak from intracellular stores and, as consequence, the apoptotic response $^{63}$ (Figure 4).

Recent data showed that IP3R-3, localized in the MAMs, has a selective role in the induction of apoptosis by preferentially transmitting apoptotic $\mathrm{Ca}^{2+}$ signals to mitochondria. ${ }^{64,65}$ Accordingly, siRNA silencing of IP3R-3 blocked apoptosis, ${ }^{65}$ as KO of IP3R-3 significantly decreased agonistinduced mitochondrial $\mathrm{Ca}^{2+}$ uptake. $^{66}$

IP3Rs possess consensus sequences for phosphorylation by numerous kinases, including protein kinase $B$ (Akt/PKB). ${ }^{60}$ This is an interesting observation, because in some cancer cells in which Akt is constitutively active (e.g., prostatic carcinoma cells), IP3Rs are hyper-phosphorylated. ${ }^{60}$ In turn, the hyper-phosphorylation of IP3Rs by Akt inhibits ER $\mathrm{Ca}^{2+}$ release and reduces significantly cellular sensitivity to $\mathrm{Ca}^{2+}$-mediated pro-apoptotic stimulation. ${ }^{62,67}$

Interestingly, similarly to $\mathrm{Bcl}-2$ with IP3R-1, the tumor suppressor PML was found to physically interact with IP3R-3 modulating its phosphorylation state. Indeed in MEF $\mathrm{Pm}^{-1}$ cells, IP3R-3 is hyper-phosphorylated. This was demonstrated to be mediated by a specific multi-protein complex, localized at ER/MAMs contact sites, including PML, IP3R-3, the protein phosphatase PP2a, and Akt. In particular, PML appeared to be essential for the binding of PP2a to the IP3R-3, hence favoring IP3R-3 de-phosphorylation (Figures 3 and 4). 
Thus in the absence of PML, the unopposed action of Akt at ER due to an impaired PP2a activity leads to a hyperphosphorylation of IP3R-3 and in turn a reduced $\mathrm{Ca}^{2}+$ flux from ER to mitochondria rendering cells resistant to apoptotic $\mathrm{Ca}^{2+}$-dependent stimuli ${ }^{30}$ (Figures 3 and $4 \mathrm{~b}$ ).

The elucidation of the role of IP3R-3 in $\mathrm{Ca}^{2+}$ transfer from the ER to mitochondria, of its molecular mechanism and of the regulatory effect of its phosphorylation may reveal a novel unexplored pharmacological target in apoptosis.

\section{Conclusions and Future Directions: Beyond the PML-NB}

PML is a critical and essential regulator of multiple apoptotic responses. While the reported role of $P M L$ in the modulation of p53 transcription could explain some of its pro-apoptotic functions, it failed to reconcile the fundamental role played by $\mathrm{PML}$ in the transcription-independent early apoptotic response.

The identification of PML at the ER-MAMs regions addressed this outstanding question. Indeed, the unexpected extra-nuclear MAMs-associated PML-dependent pathway for the control of $\mathrm{Ca}^{2+}$ homeostasis and in turn $\mathrm{Ca}^{2+}$-dependent apoptosis provides a compelling explanation for such a pleiotropic role. PML exerts this role by orchestrating at ER/MAMs sites, as in the NBs, the function of different key proteins involved in cell death processes.

Further experiments will address whether this function is required also in vivo for tissue homeostasis, and in which tissues this function is critical. The generation of an inducible erPML transgenic mouse model will also allow to determine whether the PML function at the ER/MAMs sites is fundamental (and sufficient) to trigger $\mathrm{Ca}^{2+}$-dependent apoptosis in tumor models.

Strikingly, the final outcome of a PML functional loss at the cellular level is similar to the one observed in cells overexpressing $\mathrm{Bcl}-2$ or lacking of Bax/Bak (albeit through a completely different molecular mechanism): a reduced mitochondrial $\mathrm{Ca}^{2+}$ overload upon pro-apoptotic stimuli that dramatically blunts the apoptotic response.

This in turn highlights a new extra-nuclear PML function critical for regulation of cell survival through the ER-mitochondria $\mathrm{Ca}^{2+}$-dependent cross-talk.

\section{Conflict of interest}

The authors declare no conflict of interest.

Acknowledgements. We thank members of Pinton and Pandolfi laboratories for critical discussion and suggestions. This research was supported by the Italian Association for Cancer Research (AIRC), Telethon (GGP09128), local funds from the University of Ferrara, the Italian Ministry of Education, University and Research (COFIN), the Italian Cystic Fibrosis Research Foundation, and Italian Ministry of Health to PP as well as to NIH grants to PPP.

1. Pandolfi PP. Oncogenes and tumor suppressors in the molecular pathogenesis of acute promyelocytic leukemia. Hum Mol Genet 2001; 10: 769-775.

2. Salomoni P, Pandolfi PP. The role of PML in tumor suppression. Cell 2002; 108: 165-170.

3. Salomoni $\mathrm{P}$, Ferguson BJ, Wyllie AH, Rich $\mathrm{T}$. New insights into the role of PML in tumour suppression. Cell Res 2008; 18: 622-640.

4. Bernardi R, Pandolfi PP. Structure, dynamics and functions of promyelocytic leukaemia nuclear bodies. Nat Rev Mol Cell Biol 2007; 8: 1006-1016.
5. Jensen K, Shiels $C$, Freemont PS. PML protein isoforms and the RBCC/TRIM motif. Oncogene 2001; 20: 7223-7233.

6. Lallemand-Breitenbach V, de The H. PML nuclear bodies. Cold Spring Harb Perspect Biol 2010; 2: a000661.

7. Shen TH, Lin HK, Scaglioni PP, Yung TM, Pandolfi PP. The mechanisms of PML-nuclear body formation. Mol Cell 2006; 24: 331-339.

8. Melnick A, Licht JD. Deconstructing a disease: RARalpha, its fusion partners, and their roles in the pathogenesis of acute promyelocytic leukemia. Blood 1999; 93: 3167-3215.

9. Rego EM, Wang ZG, Peruzzi D, He LZ, Cordon-Cardo C, Pandolfi PP. Role of promyelocytic leukemia (PML) protein in tumor suppression. $J$ Exp Med 2001; 193 : 521-529.

10. Song MS, Salmena L, Carracedo A, Egia A, Lo-Coco F, Teruya-Feldstein $\mathrm{J}$ et al. The deubiquitinylation and localization of PTEN are regulated by a HAUSP-PML network. Nature 2008; 455: 813-817.

11. de The H, Chen $\mathrm{Z}$. Acute promyelocytic leukaemia: novel insights into the mechanisms of cure. Nat Rev Cancer 2010; 10: 775-783.

12. Wang ZG, Ruggero D, Ronchetti S, Zhong S, Gaboli M, Rivi R et al. PML is essential for multiple apoptotic pathways. Nat Genet 1998; 20: 266-272.

13. Bernardi R, Papa A, Pandolfi PP. Regulation of apoptosis by PML and the PML-NBs. Oncogene 2008; 27: 6299-6312.

14. Takahashi Y, Lallemand-Breitenbach V, Zhu J, de The H. PML nuclear bodies and apoptosis. Oncogene 2004; 23: 2819-2824.

15. Louria-Hayon I, Grossman T, Sionov RV, Alsheich O, Pandolfi PP, Haupt Y. The promyelocytic leukemia protein protects p53 from Mdm2-mediated inhibition and degradation. J Biol Chem 2003; 278: 33134-33141.

16. Alsheich-Bartok O, Haupt S, Alkalay-Snir I, Saito S, Appella E, Haupt Y. PML enhances the regulation of p53 by $\mathrm{CK} 1$ in response to DNA damage. Oncogene 2008; 27: 3653-3661.

17. Yang S, Jeong JH, Brown AL, Lee $\mathrm{CH}$, Pandolfi PP, Chung JH et al. Promyelocytic leukemia activates Chk2 by mediating Chk2 autophosphorylation. J Biol Chem 2006; 281: 26645-26654

18. Moller A, Sirma H, Hofmann TG, Rueffer S, Klimczak E, Droge W et al. PML is required for homeodomain-interacting protein kinase 2 (HIPK2)-mediated p53 phosphorylation and cell cycle arrest but is dispensable for the formation of HIPK domains. Cancer Res 2003; 63: 4310-4314.

19. Bernardi R, Pandolfi PP. Role of PML and the PML-nuclear body in the control of programmed cell death. Oncogene 2003; 22: 9048-9057.

20. Dellaire G, Bazett-Jones DP. PML nuclear bodies: dynamic sensors of DNA damage and cellular stress. Bioessays 2004; 26: 963-977.

21. Kurki S, Latonen L, Laiho M. Cellular stress and DNA damage invoke temporally distinct Mdm2, p53 and PML complexes and damage-specific nuclear relocalization. J Cell Sci 2003; 116 (Part 19): 3917-3925.

22. Everett RD, Meredith M, Orr A, Cross A, Kathoria M, Parkinson J. A novel ubiquitin-specific protease is dynamically associated with the PML nuclear domain and binds to a herpesvirus regulatory protein. EMBO J 1997; 16: 1519-1530.

23. Li M, Chen D, Shiloh A, Luo J, Nikolaev AY, Qin J et al. Deubiquitination of p53 by HAUSP is an important pathway for p53 stabilization. Nature 2002; 416: 648-653.

24. Trotman LC, Alimonti A, Scaglioni PP, Koutcher JA, Cordon-Cardo C, Pandolfi PP. Identification of a tumour suppressor network opposing nuclear Akt function. Nature 2006; 441: 523-527.

25. Trotman LC, Wang X, Alimonti A, Chen Z, Teruya-Feldstein J, Yang H et al. Ubiquitination regulates PTEN nuclear import and tumor suppression. Cell 2007; 128: 141-156.

26. Wang X, Trotman LC, Koppie T, Alimonti A, Chen Z, Gao Z et al. NEDD4-1 is a protooncogenic ubiquitin ligase for PTEN. Cell 2007; 128: 129-139.

27. Condemine W, Takahashi Y, Zhu J, Puvion-Dutilleul F, Guegan S, Janin A et al. Characterization of endogenous human promyelocytic leukemia isoforms. Cancer Res 2006; 66: 6192-6198.

28. Lin HK, Bergmann S, Pandolfi PP. Cytoplasmic PML function in TGF-beta signalling. Nature 2004; 431: 205-211.

29. McNally BA, Trgovcich J, Maul GG, Liu Y, Zheng P. A role for cytoplasmic PML in cellular resistance to viral infection. PLOS One 2008; 3: e2277.

30. Giorgi C, Ito K, Lin HK, Santangelo C, Wieckowski MR, Lebiedzinska M et al. PML regulates apoptosis at endoplasmic reticulum by modulating calcium release. Science 2010; 330: 1247-1251.

31. Giorgi C, De Stefani D, Bononi A, Rizzuto R, Pinton P. Structural and functional link between the mitochondrial network and the endoplasmic reticulum. Int J Biochem Cell Biol 2009; 41: 1817-1827.

32. Rizzuto R, Pinton P, Carrington W, Fay FS, Fogarty KE, Lifshitz LM et al. Close contacts with the endoplasmic reticulum as determinants of mitochondrial $\mathrm{Ca}^{2+}$ responses. Science 1998; 280: 1763-1766.

33. Vance JE. Phospholipid synthesis in a membrane fraction associated with mitochondria. J Biol Chem 1990; 265: 7248-7256.

34. Piccini M, Vitelli F, Bruttini M, Pober BR, Jonsson JJ, Villanova M et al. FACL4, a new gene encoding long-chain acyl-CoA synthetase 4 , is deleted in a family with Alport syndrome, elliptocytosis, and mental retardation. Genomics 1998; 47: 350-358.

35. Stone SJ, Vance JE. Phosphatidylserine synthase-1 and -2 are localized to mitochondriaassociated membranes. J Biol Chem 2000; 275: 34534-34540. 
36. Rusinol AE, Cui Z, Chen MH, Vance JE. A unique mitochondria-associated membrane fraction from rat liver has a high capacity for lipid synthesis and contains pre-Golgi secretory proteins including nascent lipoproteins. J Biol Chem 1994; 269: 27494-27502.

37. Thomson M. Does cholesterol use the mitochondrial contact site as a conduit to the steroidogenic pathway? Bioessays 2003; 25: 252-258

38. Hayashi T, Rizzuto R, Hajnoczky G, Su TP. MAM: more than just a housekeeper. Trends Cell Biol 2009; 19: 81-88.

39. Wieckowski MR, Giorgi C, Lebiedzinska M, Duszynski J, Pinton P. Isolation of mitochondria-associated membranes and mitochondria from animal tissues and cells. Nat Protoc 2009; 4: 1582-1590.

40. Mikoshiba K. IP3 receptor/Ca2+ channel: from discovery to new signaling concepts. $J$ Neurochem 2007; 102: 1426-1446.

41. Azzolin L, von Stockum S, Basso E, Petronilli V, Forte MA, Bernardi P. The mitochondrial permeability transition from yeast to mammals. FEBS Lett 2010; 584: 2504-2509.

42. Halestrap AP. What is the mitochondrial permeability transition pore? J Mol Cell Cardiol 2009; 46: 821-831

43. Berridge MJ. The endoplasmic reticulum: a multifunctional signaling organelle. Cell Calcium 2002; 32: 235-249.

44. Pinton P, Giorgi C, Siviero R, Zecchini E, Rizzuto R. Calcium and apoptosis: ERmitochondria Ca2+ transfer in the control of apoptosis. Oncogene 2008; 27: 6407-6418.

45. Rizzuto R, Marchi S, Bonora M, Aguiari P, Bononi A, De Stefani D et al. Ca(2+) transfer from the ER to mitochondria: when, how and why. Biochim Biophys Acta 2009; 1787 1342-1351.

46. Clapham DE. Calcium signaling. Cell 2007; 131: 1047-1058.

47. Ferri KF, Kroemer G. Organelle-specific initiation of cell death pathways. Nat Cell Biol 2001; 3: E255-E263.

48. Pinton P, Ferrari D, Rapizzi E, Di Virgilio FD, Pozzan T, Rizzuto R. The Ca2+ concentration of the endoplasmic reticulum is a key determinant of ceramide-induced apoptosis: significance for the molecular mechanism of Bcl-2 action. EMBO J 2001; 20: 2690-2701.

49. Pinton P, Ferrari D, Rapizzi E, Di Virgilio F, Pozzan T, Rizzuto R. The Ca2+ concentration of the endoplasmic reticulum is a key determinant of ceramide-induced apoptosis: significance for the molecular mechanism of Bcl-2 action. EMBO J 2001; 20: 2690-2701.

50. Pinton P, Ferrari D, Magalhaes P, Schulze-Osthoff K, Di Virgilio F, Pozzan T et al. Reduced loading of intracellular $\mathrm{Ca}(2+)$ stores and downregulation of capacitative $\mathrm{Ca}(2+)$ influx in Bcl-2-overexpressing cells. J Cell Biol 2000; 148: 857-862.

51. Pinton P, Ferrari D, Rapizzi E, Di Virgilio F, Pozzan T, Rizzuto R. A role for calcium in Bcl-2 action? Biochimie 2002; 84: 195-201.

52. Scorrano L, Oakes SA, Opferman JT, Cheng EH, Sorcinelli MD, Pozzan T et al. BAX and BAK regulation of endoplasmic reticulum $\mathrm{Ca} 2+$ : a control point for apoptosis. Science 2003; 300: 135-139.
53. Chami M, Prandini A, Campanella M, Pinton P, Szabadkai G, Reed JC et al. Bcl-2 and Bax exert opposing effects on $\mathrm{Ca} 2+$ signalling, which do not depend on their putative pore-forming region. J Biol Chem 2004; 279: 54581-54589.

54. Joseph SK, Hajnoczky G. IP3 receptors in cell survival and apoptosis: $\mathrm{Ca} 2+$ release and beyond. Apoptosis 2007; 12: 951-968.

55. Mikoshiba K. The IP3 receptor/Ca2+ channel and its cellular function. Biochem Soc Symp 2007; 74: 9-22

56. Jayaraman T, Marks AR. T cells deficient in inositol 1,4,5-trisphosphate receptor are resistant to apoptosis. Mol Cell Biol 1997; 17: 3005-3012.

57. Khan AA, Soloski MJ, Sharp AH, Schilling G, Sabatini DM, Li SH et al. Lymphocyte apoptosis: mediation by increased type 3 inositol 1,4,5-trisphosphate receptor. Science 1996; 273: 503-507.

58. Sugawara H, Kurosaki M, Takata M, Kurosaki T. Genetic evidence for involvement of type 1, type 2 and type 3 inositol 1,4,5-trisphosphate receptors in signal transduction through the B-cell antigen receptor. EMBO J 1997; 16: 3078-3088.

59. Boehning D, Patterson RL, Sedaghat L, Glebova NO, Kurosaki T, Snyder SH. Cytochrome c binds to inositol $(1,4,5)$ trisphosphate receptors, amplifying calcium-dependent apoptosis Nat Cell Biol 2003; 5: 1051-1061.

60. Khan MT, Wagner L, Yule DI, Bhanumathy C, Joseph SK. Akt kinase phosphorylation of nositol 1,4,5-trisphosphate receptors. J Biol Chem 2006; 281: 3731-3737.

61. Vanderheyden V, Devogelaere B, Missiaen L, De Smedt H, Bultynck G, Parys JB Regulation of inositol 1,4,5-trisphosphate-induced $\mathrm{Ca} 2+$ release by reversible phosphorylation and dephosphorylation. Biochim Biophys Acta 2009; 1793: 959-970.

62. Szado T, Vanderheyden V, Parys JB, De Smedt H, Rietdorf K, Kotelevets L et al. Phosphorylation of inositol 1,4,5-trisphosphate receptors by protein kinase B/Akt inhibits Ca2+ release and apoptosis. Proc Natl Acad Sci USA 2008; 105 2427-2432.

63. Oakes SA, Scorrano L, Opferman JT, Bassik MC, Nishino M, Pozzan T et al. Proapoptotic $B A X$ and $B A K$ regulate the type 1 inositol trisphosphate receptor and calcium leak from the endoplasmic reticulum. Proc Natl Acad Sci USA 2005; 102: 105-110.

64. Mendes CC, Gomes DA, Thompson M, Souto NC, Goes TS, Goes AM et al. The type III inositol 1,4,5-trisphosphate receptor preferentially transmits apoptotic $\mathrm{Ca} 2+$ signals into mitochondria. J Biol Chem 2005; 280: 40892-40900.

65. Blackshaw S, Sawa A, Sharp AH, Ross CA, Snyder SH, Khan AA. Type 3 inositol 1,4 5-trisphosphate receptor modulates cell death. FASEB J 2000; 14: 1375-1379.

66. Hayashi T, Su TP. Sigma-1 receptor chaperones at the ER-mitochondrion interface regulate $\mathrm{Ca}(2+)$ signaling and cell survival. Cell 2007; 131: 596-610.

67. Marchi S, Rimessi A, Giorgi C, Baldini C, Ferroni L, Rizzuto R et al. Akt kinase reducing endoplasmic reticulum $\mathrm{Ca} 2+$ release protects cells from $\mathrm{Ca} 2+$-dependent apoptotic stimuli. Biochem Biophys Res Commun 2008; 375: 501-505. 